\title{
Orthotic management of cerebral palsy: Recommendations from a consensus conference
}

\author{
Christopher Morris ${ }^{\mathrm{a}, \mathrm{b}, *}$, Roy Bowers ${ }^{\mathrm{c}}$, Karyn Ross $^{\mathrm{c}}$, Phil Stevens ${ }^{\mathrm{d}}$ and David Phillips ${ }^{\mathrm{e}}$ \\ ${ }^{a}$ Cerebra Research Unit and PenCLAHRC, Peninsula Medical School, University of Exeter, Exeter, UK \\ ${ }^{\mathrm{b}}$ Honorary Principal Orthotist, Nuffield Orthopaedic Centre, Oxford, UK \\ ${ }^{\mathrm{c}}$ National Centre for Prosthetics and Orthotics, University of Strathclyde, UK \\ ${ }^{\mathrm{d}}$ Hanger Prosthetics and Orthotics Inc, Salt Lake City, UT, USA \\ ${ }^{\text {e } O r t h o t i c ~ I n n o v a t i o n s, ~ M e l b o u r n e, ~ V i c t o r i a, ~ A u s t r a l i a ~}$
}

\begin{abstract}
An international multidisciplinary group of healthcare professionals and researchers participated in a consensus conference on the management of cerebral palsy, convened by the International Society for Prosthetics and Orthotics. Participants reviewed the evidence and considered contemporary thinking on a range of treatment options including physical and occupational therapy, and medical, surgical and orthotic interventions. The quality of many of the reviewed papers was compromised by inadequate reporting and lack of transparency, in particular regarding the types of patients and the design of the interventions being evaluated. Substantial evidence suggests that ankle-foot orthoses (AFOs) that control the foot and ankle in stance and swing phases can improve gait efficiency in ambulant children (GMFCS levels I-III). By contrast, little high quality evidence exists to support the use of orthoses for the hip, spine or upper limb. Where the evidence for orthosis use was not compelling consensus was reached on recommendations for orthotic intervention. Subsequent group discussions identified recommendations for future research. The evidence to support using orthoses is generally limited by the brevity of follow-up periods in research studies; hence the extent to which orthoses may prevent deformities developing over time remains unclear. The full report of the conference can be accessed free of charge at www.ispoint.org.
\end{abstract}

Keywords: Cerebral palsy, orthoses, orthotic, evidence-based, consensus

\section{Introduction}

An international, multidisciplinary group of 24 academics, healthcare professionals and research scientists with expertise in cerebral palsy $(\mathrm{CP})$ participated in a consensus conference convened by the International Society for Prosthetics and Orthotics. The conference was held at Wolfson College, Oxford, in September 2008. Conference participants reviewed the evidence and considered contemporary thinking on a range of

\footnotetext{
* Corresponding author: Chris Morris, Cerebra Research Unit and PenCLARHC, Child Health Group, Veysey Building, Salmon Pool Lane, University of Exeter, Exeter, Devon EX2 4SG, UK. Tel.: +44 1392 262980; Fax: +44 1392 262964; E-mail: chris.morris@ pms.ac.uk.
}

treatment options including physical and occupational therapy, and medical, surgical and orthotic interventions. The report of the conference contains the manuscripts of all the presentations and 'Conclusions and Recommendations' from the meeting [61]. The purpose of this paper is to present the findings relating specifically to the orthotic management of CP. First, it is important to consider some general observations and recommendations to put orthotic management in context.

The aim of healthcare for people with $\mathrm{CP}$ is to enable culturally appropriate activities and participation by promoting efficient movement, limiting deformity, reducing pain, and employing cognitive and/or behavioural strategies. Healthcare for people with $\mathrm{CP}$ requires the skills and input of a variety of professions 
who must work efficiently and collaboratively with the family as a team. Each member of the teams involved in managing different issues (e.g. orthopaedic, epilepsy, feeding etc) must understand the range of problems associated with the condition as well as the family's goals and priorities [61].

Health professionals working with disabled people should become familiar with the concepts espoused in the World Health Organisation International Classification of Functioning, Disability and Health (ICF) [117]. The conference report recommends the definition of CP reported by Rosenbaum et al. in 2007 [90], and the classification of type and distribution of impairment presented by the Surveillance of Cerebral Palsy in Europe [104]. The report also recommends that function be classified using valid and reliable systems such as the Gross Motor Function Classification System (GMFCS) [74,75] and Manual Ability Classification System (MACS) [24].

The GMFCS was developed as a valid and reliable way to classify a child's movement ability in sitting, standing and walking into one of five levels [74]. Similarly, the MACS is a five level system for classifying a child's ability to handle everyday objects [24]. These functional classification systems enable people to communicate with each other more clearly, including parents, who appear to find these 'levels' of function both acceptable and useful in understanding their child's status [57-59]. The GMFCS can also be used to inform prognosis for the development of movement ability as a child grows, and to monitor progress. While indications for the prescription of orthoses are principally determined by functional and neurobiomechanical deficits, orthotic management can also be approached by considering GMFCS levels [56,60].

\subsection{GMFCS levels I, II and III}

The goals of orthotic treatment for children in GMFCS levels I-III are mostly related to the lower limb and aim to improve and maintain an efficient gait, although prevention of deformity is also important. Gait can be classified in the sagittal plane for people with spastic hemiplegia according to the systems proposed by Winters, Gage and Hicks [116] or the Melbourne group [85,86]. Similarly, the system proposed by Sutherland and Davids can be used for people with bilateral CP [105]. However, while existing gait classifications are useful, particularly when learning about $\mathrm{CP}$ gait, the reliability of such classifications is not well determined and not all children will be readily classified.

\subsection{GMFCS levels $I V$ and $V$}

Children in GMFCS levels IV and V are more at risk of associated impairments; these particularly include limitations in speech and vision, and to some extent also limitations in hearing and cognition [42]. Children who have limited or no movement ability are at greater risk of hip subluxation and/or scoliosis (see below). The goals of orthotic management for people in GMFCS levels IV and V are therefore different to those for people in GMFCS levels I-III. There is greater emphasis on preventing spinal and hip deformities, and improving sitting posture for functional and social reasons. Orthoses can also be used to enable upright standing and weight-bearing, with potential physiological and psychosocial benefits. Unfortunately there is little or no evidence regarding the extent to which these benefits are achievable in practice. Research is required to inform effective methods and regimens for weightbearing programmes.

\subsection{Prescription of orthoses}

Dialogue between the child and family, the orthotist and other members of the team (therapist, physician, surgeon, bioengineer etc.) is essential when deciding upon treatment goals and the biomechanical objectives to achieve these goals. The role of the orthotist is to design, fit, align, deliver and review the orthosis which will, in theory, achieve the biomechanical objectives agreed by the team. When an orthosis is prescribed consideration must be given as to when, and for how long in each twenty-four hour period it should be worn. Adherence to orthotic management regimens is likely to be better when there is clear agreement between therapists and the orthotist regarding the treatment regimen, and the family fully understands the rationale for the prescription.

\section{Lower $\operatorname{limb}$}

Orthoses should be prescribed to address specific functional or neurobiomechanical deficits. The most commonly used lower limb orthoses in CP are AFOs which provide direct control of the ankle and foot to improve gait. Although swing phase equinus presents a tripping hazard, significant problems can also occur during the stance phase of gait. Gait deviations observed at the knee and the hip are often secondary to poor foot alignment during stance. Dependant on their 
design, some AFOs can provide indirect control of the knee and hip joints. This combination of direct and indirect joint control can reduce the neurobiomechanical challenge facing the patient, improving mobility.

\subsection{Effect on temporal-spatial parameters of gait}

Temporal-spatial gait parameters are the most commonly reported outcome measures in studies on the effects of AFOs in CP. The majority of studies investigating the effect of AFOs on velocity report increased velocity $[1,2,9,20,22,38,88,108,110,114]$, although most studies focusing on exclusively diplegic subjects report little or no effect $[13,15,45,80,83,99]$. AFOs have been found to significantly reduce cadence $[9,12,38$, $79,88,108,110,114]$ but as with velocity, their effect on diplegic subjects is equivocal, with two studies only reporting a reduction $[13,15]$, and the majority reporting no change $[1,15,38,45,80,83,99]$. AFO use has been demonstrated to increase step length $[9,12,13,20,38,87$, $88,108,110,114]$, stride length $[1,2,9,12,13,15,18,22$, $38,45,79,80,87,88,114]$, and the duration of single support $[1,2,9,114]$. However, the effect on double support is unclear, with some papers reporting a beneficial decrease $[1,2,38]$, and others reporting an increase [9, 83 ] or no effect [88].

\subsection{Direct and indirect biomechanical effects}

AFOs can improve ankle kinematics $[1,2,9,12,13,15$, $18,20,37,38,45,52,70,79,80,83,87,88,99,108,110]$. Inevitably, orthoses that restrict ankle joint motion reduce power generation and absorption at the ankle [1, $2,12,13,20,70,80,83,87]$, but this may be an acceptable compromise in order to optimise other gait parameters and overall efficiency. Solid AFOs can help increase the 2 nd peak of the ground reaction force (GRF) in the propulsive phase of gait $[15,45]$. Improvements in the skeletal alignment of the foot and ankle have been shown radiographically whilst wearing AFOs [113]. However, it is not known what influence this may have on skeletal development in the growing child.

AFOs have been shown to improve kinetics and kinematics at the knee $[1,9,12,13,20,27,45,46,52,87,88,99$, $110]$ and hip $[1,9,18,110]$, but not the pelvis. The arc of motion permitted by flexible or hinged AFOs, and the stiffness and alignment of solid AFOs [102] are critical if the GRF is to be successfully manipulated to influence the proximal joints. There is emerging evidence that 'tuning' solid AFOs (adjusting sagittal plane alignment) can significantly improve their effect at the proximal joints and as a consequence, the gait of the user $[14,71,102]$. Some angle of forward inclination of the tibia appears to be optimal $[68,71,110]$ even when the AFO has been cast in plantarflexion to accommodate gastrocnemius contracture. Tuning may be compromised by the presence of ataxia, or by proximal contractures which may need to be addressed to improve outcomes [14]. In some cases footwear modifications can be beneficial to optimise entrance to and exit from stance $[68,72]$.

\subsection{Metabolic and cardiopulmonary effects}

The metabolic cost of walking may be decreased by AFO use, indicating improved energy efficiency [2,12, $13,53,62,99]$. In some studies where walking speed was controlled, AFO use decreased oxygen consumption $[2,13,53]$. In other studies oxygen consumption was unchanged, but self-selected walking speed increased $[12,13]$.

\subsection{Effect on muscle}

It is unclear whether and how AFOs influence the phasic activity of lower limb muscles. It is also unclear whether AFOs can maintain or increase muscle length and hence prevent or reduce deformity developing over time. A minimum of six hours of stretching per day is proposed to be beneficial in maintaining length of the soleus muscle. [106] It is possible that use of solid AFOs for prolonged daily periods may also confer this effect, potentially reducing the need for Achilles tendon surgery [92]. The long term effects of AFOs on muscle strength are unknown, and should be investigated.

\subsection{Effect on function and ability}

Understandably, no papers were identified relating to the sit-to-stand (STS) manoeuvre in hemiplegic subjects. In diplegic subjects, there is some evidence that AFOs can be beneficial [76,115], particularly in those whose performance without orthoses was more than one standard deviation slower than normal [115]. While dorsiflexion has been identified as the only consistent strategy to improve STS [115], the use of ankle joints in the presence of gastrocnemius contracture is controversial. Although permitting dorsiflexion may improve the STS task, it may be detrimental to walking performance and precipitate progression of deformity. Solid AFOs that maintain the tibia in a position close to vertical may impede STS, whereas those tuned to a 
position of some forward inclination of the tibia to optimise gait may facilitate STS. One study suggests that stair ambulation is not impaired by AFO use [98] There is some evidence that AFOs can improve standing balance $[10,27,40,112]$. However, a single study on sitting balance [3], and three on upper limb function [9,13,54], provide little evidence in support of AFOs affecting either.

Studies on the effectiveness of AFOs in CP have been almost exclusively conducted on children and young adults, and longitudinal studies investigating the longterm effects of AFO use are rare. The quality of many studies is compromised by failure to provide adequate detail about the subjects in the study, the intervention being investigated, and/or the methodology. If this level of detail is routinely provided in future studies, and ambiguous terminology can be avoided, then research can be more effectively converted into clinical practice, to the benefit of all orthosis users. Although lower limb orthoses are sometimes used in GMFCS levels IV and V in conjunction with standing frames, or with the intention of improving foot and ankle posture and alignment, such as on wheelchair footplates, or to influence sitting balance, there is no research evidence to demonstrate their efficacy when used in these ways. There is scant literature reporting on the perceptions of orthosis users and/or their carers regarding the value of AFO use [64].

\section{Hip}

Hip subluxation and dislocation, often accompanied by pain, compromised sitting stability and increased risk of pressure ulcers, is a common challenge in the management of CP. Hip subluxation appears to be strongly correlated with movement ability as an almost linear increase in risk has been reported with increasing GMFCS level [36,100]. Additionally, children with Winters' type IV hemiplegia [116] are at an increased risk for the development of late onset hip subluxation which can be extremely disabling. Therefore all staff involved in the care of children with $\mathrm{CP}$ should be aware of the risk factors for hip dislocation and a designated member of the team must take responsibility for the hip surveillance of each child.

Various hip abduction orthoses and postural management systems have been proposed to discourage hip subluxation [7,35,39,63,77]. However, reports of poor patient adherence to using such devices, and general concerns among orthopaedic surgeons about effica- cy, raise doubts about the ability of postural management approaches to maintain hip congruency $[6,21,34$, 39]. While data from clinical trials is scarce, one randomised controlled trial evaluated a protocol in which a variable abduction hip orthosis was combined with regular botulinum A toxin injections to the adductors and hamstrings in children in GMFCS levels IV and $\mathrm{V}$. The results indicated that this treatment regimen did not substantially discourage hip subluxation [33], nor did it improve gross motor function relative to matched, untreated controls [8], Hip surgery should be considered when the subluxation exceeds 30 percent of the migration index; and outcomes are thought to be better when surgery is performed as soon as indicated rather than being delayed using alternative interventions.

\section{Spine}

Scoliosis is frequently observed in children and adults with CP. Natural history studies indicate that non-ambulant subjects with bilateral $\mathrm{CP}$, consistent with GMFCS levels IV and V, appear to be at the greatest risk [51,91]. The emergence and progression of scoliosis does not appear to be associated with the type of $\mathrm{CP}$, such as spastic, dyskinetic or ataxic [51]. However, there is conflicting evidence with respect to possible associations between the presence of pelvic obliquity and hip dislocation and the onset and progression of scoliosis [51]. In addition, some children undergoing selective dorsal rhizotomy appear to be at some risk for the development of scoliosis and other spinal deformities [30,50,41,101,103,109]. Similarly, there are conflicting reports regarding the use of intrathecal Baclofen and its effects on the progression of scoliosis [29, 93,94,97].

Current evidence suggests that while spinal orthoses may slow the rate of progression, scoliosis will typically deteriorate despite orthotic intervention [55,69, 107]. Therefore surgical correction is often considered for major curves in order to more permanently improve posture, facilitate better seating position, reduce pain and discomfort, and reduce caregiver burden. The characteristics of those subjects who respond better to spinal orthoses are poorly understood. However, more flexible curves and good initial in-brace correction appear to be possible indicators of more successful bracing outcomes $[44,107]$. To the limited extent that it has been investigated, there is no evidence that the use of spinal orthoses in CP compromises pulmonary function or oxygen saturation levels $[47,48]$. Spinal orthoses 
have consistently been associated with improvements in sitting stability and postural control of the head and upper limbs $[49,107,111]$. In summary, while it is generally accepted that spinal orthoses rarely halt progression of scoliosis in children with CP, they may delay it, and by stabilising trunk posture, they can provide other substantive benefits, particularly for children for whom surgery is not feasible.

\section{Upper limb}

Little evidence exists with regard to the orthotic management of flexion spasticity and contracture at the elbow and wrist. A hybrid treatment approach of dynamic assistive bracing coupled with electrical stimulation across the elbow and wrist joints appears to be effective in reducing upper extremity tone, and improving dexterity and grip in subjects with hemiplegia [73,96]. However, the treatment effect has not been shown to endure once the modalities have been discontinued [73, 96]. The use of an extension-assist orthosis as an adjunct to botulinum toxin A injections and serial casting has been reported in small case series [118,119].

Wrist and hand function can be adversely affected by spasticity. Ulnar deviation, wrist flexion, thumb adduction posturing and contractures are commonly observed. The use of various hand splints has been suggested to prevent progressive contracture of these spastic muscles and to assist in motor control functions such as grip, pinch and dexterity [16,19,26,28,31,81]. Among subjects with hemiplegia, dynamic thermoplastic orthoses allowing limited flexion and extension at the wrist appear to facilitate better function than static orthoses in tasks that require grip and dexterity [11]. However, these orthoses may compromise lateral pinch strength relative to the unbraced condition [11] Static wrist-hand orthoses do not appear to improve immediate function relative to dynamic bracing and unbraced conditions [11]. The ability of orthoses to prevent or delay wrist and hand contractures has not been evaluated.

\section{Lycra ${ }^{\circledR}$ orthoses}

Several types of Lycra ${ }^{\circledR}$-based orthoses have appeared in the last ten years, with designs ranging from full body suits to smaller garments such as sleeves/gloves and leggings. Some children with CP appear to experience functional gains by using Lycra ${ }^{\circledR}$. based orthoses; however, others experience difficulties with donning and doffing, feel hot and/or restricted, have problems with toileting in full suits, or experience compromised respiratory function $[4,65,66]$. Synthesis of evidence from studies evaluating Lycra ${ }^{\circledR}$-based orthoses is made difficult by the heterogeneity of the orthoses investigated, the various types of $\mathrm{CP}$ treated and outcomes measured. Hence the characteristics of people who may benefit from using Lycra ${ }^{\circledR}$ garments are not well defined in the literature. The effectiveness of Lycra ${ }^{\circledR}$-based orthoses to improve function is not established, and should be evaluated carefully, in a research context.

\section{Recommendations for orthotic research}

Unfortunately, research studies evaluating the effects of orthoses for people with cerebral palsy often lack a well specified research question, sufficient detail of the methodology, and adequate description of the subjects and/or the intervention. There is often a lack of clarity about what is being evaluated in orthotic research studies. Hence, frequently, it is difficult to make use of published research either to generalise in clinical settings or to inform future research. Papers should include a well constructed research question, the research methodology, and the outcomes being assessed. It should made clearer how research investigating the biomechanical effect of an orthosis (e.g. improving gait pattern in the gait laboratory) might translate into improving function in a person's daily life in their normal environment. Almost all studies evaluating the effectiveness of orthoses are cross-sectional in design; longitudinal studies are recommended to assess the longterm impact of orthoses. It is recommended that any project investigating the use of orthoses should include an orthotist as an integral member of the research team.

Reports of orthotic research studies require a minimum dataset describing the subjects and the orthosis being used in the investigation. The minimum dataset of details of people with CP should include age, sex, type and distribution of CP, GMFCS level and/or MACS level (for studies of the upper limb) and whether subjects have had recent surgery or pharmacological intervention. Journal editors find reporting guidelines useful to aid them in assessing the quality of papers submitted for publication; for further details see The EQUATOR Network (www.equator-network.org). It is acknowledged that comprehensive reporting of such details increases the length of research papers, but it is necessary for appreciation of what was done in the study, and for the findings to be usefully applied by others. 


\section{Research involving ankle foot orthoses}

The most common topic for orthotic research and CP has been the effects of AFOs. Description of the subjects should include range of motion (ROM) of all lower limb joints, highlighting whether range is attained with ease or difficulty. Particular reference should be paid to dorsiflexion range with knee extended, which is an indication of gastrocnemius length. Any fixed deformities (including rotational deformity) should be reported, together with an assessment of muscle spasticity and strength. A description of gait, both with and without orthoses if appropriate, should be provided, stating whether or not mobility aids are used.

A minimum description of AFOs used to improve gait should included the design and construction of the orthosis, alignment of the leg in the orthosis, alignment of the orthosis to the ground in footwear, and the footwear design. The description of design and construction should include whether it is custom-made or prefabricated, materials (type and thickness), trimlines including foot plate length, type of any ankle articulations and range of motion permitted by these (or by flexible AFO designs), and the type and location of straps and fastenings. The foot and ankle alignment imposed by the AFO should be described in the sagittal, coronal and transverse planes. The alignment of the AFO and leg in the sagittal plane when the subject is standing wearing the orthosis with footwear should be stated. Details of the footwear should include the pitch (heel-sole differential), the design of the heel, the stiffness of the sole, the sole profile, and any additional footwear modifications. The optimum duration of use (dose) remains to be established and occurrence of sideeffects (pressure sores, disturbed sleep, etc.) should be evaluated and reported. A recent systematic review by Ridgewell and colleagues echoes many of the recommendations regarding appropriate reporting of research evaluating AFOs with children with CP [84]. It is to be hoped that any future consensus conferences on $\mathrm{CP}$ will be able to draw on more complete and transparent research reports of larger number of subjects and longer durations of follow up.

\section{References}

[1] M.F. Abel, G.A. Juhl, C.L. Vaughan, D.L. Damiano. Gait assessment of fixed ankle-foot orthoses in children with spastic diplegia, Archives of Physical Medicine and Rehabilitation 79(2) (1998), 126-133.
[2] B. Balaban, E. Yasar, U. Dal, K. Yazicioglu, H. Mohur and T.A. Kalyon, The effect of hinged ankle-foot orthosis on gait and energy expenditure in spastic hemiplegic cerebral palsy, Disability and Rehabilitation 29(2) (2007), 139-144.

[3] R.B. Beals, Resident's forum. The possible effects of solid ankle-foot orthoses on trunk posture in the nonambulatory cerebral palsy population: a preliminary evaluation, Journal of Prosthetics and Orthotics 13(2) (2001), 34-38.

[4] M. Blackmore, S.A. Garbellini, P.J. Buttigieg and J. Wells, (2006) A systematic review of the effects of soft splinting on upper limb function in people with cerebral palsy: American Academy for Cerebral Palsy and Developmental Medicine Evidence Report. http://new.aacpdm.org/membership/out come/resources/Softsplintingreview.pdf Accessed 2 June 2010.

[5] E. Blair, J. Ballantyne, S. Horsman and P. Chauvel, A study of a dynamic proximal stability splint in the management of children with cerebral palsy, Developmental Medicine and Child Neurology 37 (1995), 544-554.

[6] E. Bleck. Orthopaedic management in cerebral palsy. Clinics in Developmental Medicine (Nos 99/100). Mac Keith Press, London.

[7] E. Bower. Hip abduction and spinal orthosis in cerebral palsy, Physiotherapy 76 (1990), 658-659.

[8] R.N. Boyd, F. Dobson, J. Parrott, S. Love, J. Oates, A. Larson, G. Burchall, P. Chondros, J. Carlin, G. Nattrass and H.K. Graham, The effect of botulinum toxin type A and a variable hip abduction orthosis on gross motor function: a randomized controlled trial, European Journal of Neurology 8 (2001), 109-119.

[9] R. Brunner, G. Meier and T. Ruepp, Comparison of a stiff and a spring-type ankle-foot orthosis to improve gait in spastic hemiplegic children, Journal of Pediatric Orthopaedics 18 (1998), 719-726.

[10] P.A. Burtner, M.H. Woollacott and C. Qualls, Stance balance control with orthoses in a group of children with spastic cerebral palsy, Developmental Medicine and Child Neurology 41(11) (1999), 748-757.

[11] P. Burtner, J. Poole, T. Torres, A.M. Medora, R. Abeyta, J. Keene and C. Qualls, Effect of wrist hand splints on grip, pinch, manual dexterity and muscle activation in children with spastic hemiplegia: a preliminary study, Journal of Hand Therapy 21 (2008), 36-42.

[12] C.E. Buckon, S.S. Thomas, S. Jakobson-Huston, M. Sussman and M. Aiona, Comparison of three ankle-foot orthosis configurations for children with spastic hemiplegia, Developmental Medicine and Child Neurology 43 (2001), 371-378.

[13] C.E. Buckon, S.S. Thomas, S. Jakobson-Huston, M. Sussman and M. Aiona, Comparison of three ankle-foot orthosis configurations for children with spastic diplegia, Developmental Medicine and Child Neurology 46(9) (2004), 590-598.

[14] P.B. Butler, S.E. Farmer, C. Stewart, P.W. Jones and M. Forward, The effect of fixed ankle foot orthoses in children with cerebral palsy, Disability and Rehabilitation: Assistive Technology 2(1) (2007), 51-58.

[15] W.E. Carlson, C.L. Vaughan, D.L. Damiano and M.F. Abel, Orthotic management of gait in spastic diplegia, American Journal of Physical Medicine and Rehabilitation 76(3) (1997), 219-225.

[16] J. Carmick, Use of neuromuscular electrical stimulation and a dorsal wrist splint to improve the hand function of a child with spastic hemiparesis, Physical Therapy 77 (1997), 661671. 
[17] K. Corn, C. Imms, G.Timewell, C. Carter, L. Collins, S. Dubbeld, S. Schubiger and E. Froude, Impact of second skin lycra splinting on the quality of upper limb movement in children, British Journal of Occupational Therapy 66 (2003), 464-472.

[18] S. Crenshaw, R. Herzog, P. Castagno, J. Richards, F. Miller, G. Michaloski and E. Moran, The efficacy of tone-reducing features in orthotics on the gait of children with spastic diplegic cerebral palsy, Journal of Pediatric Orthopedics 20(2) (2000), 210-216.

[19] D. Currie and A. Mendiola, Cortical thumb orthosis for children with spastic hemiplegic cerebral palsy, Arch Phys Med Rehabil 68 (1987), 214-216.

[20] K. Desloovere, G. Molenaers, L. Van Gestel, C. Huenaerts, A. Van Campenhout, B. Callewaert, P. Van de Walle and J. Seyler, How can push-off be preserved during use of an ankle foot orthosis in children with hemiplegia? A prospective controlled study. Gait and Posture 24(2) (2006), 142-151.

[21] F. Dobson, R. Boyd, J. Parrott, G.R. Nattrass and H.K. Graham, Hip surveillance in children with cerebral palsy. Impact on the surgical management of spastic hip disease, Journal of Bone and Joint Surgery Br 84 (2002), 720-726.

[22] E. Dursun, N. Dursun and D. Alican, Ankle-foot orthoses: effect on gait in children with cerebral palsy, Disability and Rehabilitation 24(7) (2002), 345-347.

[23] J Edmonson, K Fisher and C Hanson, How effective are Lycra suits in the management of children with cerebral palsy? Journal of the Association of Paediatric Chartered Physiotherapists 90 (1999), 49-57.

[24] A.C. Eliasson, L. Krumlinde Sundholm, B. Rösblad, E. Beckung, M. Arner, A.-M. Öhrvall and P. Rosenbaum, The Manual Ability Classification System (MACS) for children with cerebral palsy: scale development and evidence of validity and reliability, Dev Med Child Neurol 48 (2006), 549-554.

[25] D. Embrey and S. Westcott, Effects of the standing walking and sitting hip orthosis in children with spastic cerebral palsy: surface electromyographic evidence, Pediatric Physical Therapy 18 (2006), 74-75.

[26] C. Exner and B. Bonder, Comparative effects of three hands splints on bilateral hand use, grasp, arm-hand posture in hemiplegic children: a pilot study, Occup Ther J Res 3 (1983), 77-92.

[27] S.E. Farmer, P.B. Butler and R.E. Major, Targeted Training for Crouch Posture in Cerebral Palsy: A case report, Physiotherapy 85(5) (1999), 242-247.

[28] J. Flegle and J. Leibowitz, Improvements in grasp skill in children with hemiplegia with the MacKinnon splint, Res Dev Disabil 9 (1998), 145-151.

[29] G.M. Ginsburg and A.J. Lauder, Progression of scoliosis in patients with spastic quadriplegia after the insertion of an intrathecal baclofen pump, Spine 32(24) (2007), 2745-2750.

[30] J.D. Golan, J.A. Hall, G. O'Gorman, C. Poulin, T.E. Benaroch, M.A. Cantin and J.P. Farmer, Spinal deformities following selective dorsal rhizotomy, J Neurosurg 106(6 Suppl) (2007), 441-449.

[31] G. Goodman and S. Bazyk, The effects of short thumb opponens splint in hand function in cerebral palsy, Am J Occup Ther 45 (1990), 726-731.

[32] G. Gordon and D. Simkiss, A systematic review of the evidence for hip surveillance in children with cerebral palsy, $J$ Bone Joint Surg Br 88 (2006), 1492-1496.

[33] H.K. Graham, R. Boyd, J.B. Carlin, F.Dobson, K.Lowe, G. Nattrass, P. Thomason, R. Wolfe and D. Reddihough, Does botulinum toxin A combined with bracing prevent hip dis- placement in children with cerebral plasy and "hips at risk"? A randomized, controlled trial, J Bone Joint Surg 90 (2008), 23-33.

[34] H.K. Graham, Mechanisms of deformity, in: Management of the Motor Disorders of Children with Cerebral Palsy, (2nd ed.), D. Scrutton, D. Damiano and M. Mayston, eds, Mac Keith Press, London, 2004, pp. 105-129.

[35] D. Grogan, M. Lundy and J. Ogden, A method for early postoperative mobilatization of the cerebral play patient using a removable abduction bar, J Pediatr Orthop 7 (1987), 338-340.

[36] G. Hägglund, H. Lauge-Pedersen and P. Wagner, Characteristics of children with hip displacement in cerebral palsy, BMC Musculoskelet Disord 8 (26 Oct 2007), 101.

[37] F. Hainsworth, M.J. Harrison, T.A. Sheldon and S.H. Roussounis, A preliminary evaluation of ankle orthoses in the management of children with cerebral palsy, Developmental Medicine and Child Neurology 39(4) (1997), 243-247.

[38] S. Hayek, Y. Hemo, S. Chamis, R. Bat, E. Segev, S. Wientroub and Z. Yzhar, The effect of community-prescribed ankle - foot orthoses on gait parameters in children with spastic cerebral palsy, Journal of Children's Orthopaedics 1(6) (2007), 325-332.

[39] M.M. Hoffer, Management of the hip in cerebral palsy, $J$ Bone Joint Surg 68 (1986), 629-631.

[40] K. Jesinkey, A. Näslund and H. Hirschfeld, Initiation of reaching when standing with and without DAFOs in children with spastic diplegia, Advances in Physiotherapy 7(4) (2005), 144-153.

[41] M.B. Johnson, L. Goldstein, S.S. Thomas, J. Piatt, M. Aiona and M. Sussman, Spinal deformity after selective dorsal rhizotomy in ambulatory patients with cerebral palsy, J Pediatr Orthop 24(5) (2004), 529-536.

[42] J. Kennes, P. Rosenbaum, S.E. Hanna, S. Walter, D. Russell, P. Raina, D. Bartlett and B. Galuppi, Health status of school-aged children with cerebral palsy: information from a population-based sample, Dev Med Child Neurol 44(4) (2002), 240-247.

[43] V. Knox, The use of lycra garments in children with cerebral palsy: a report of a descriptive clinical trial, Brit J Occup Ther 66 (2003), 71-77.

[44] T. Kotwicki and J. Marek, Conservative management of neuromuscular scoliosis: personal experience and review of literature, Disabil Rehabil 30 (2008), 792-798.

[45] W.K. Lam, J.C. Leong, Y.H. Li, Y. Hu and W.W. Lu. Biomechanical and electromyographic evaluation of ankle foot orthosis and dynamic ankle foot orthosis in spastic cerebral palsy, Gait and Posture 22(3) (2005), 189-197.

[46] R. Lampe, J. Mitternacht, S. Schrödl, L. Gerdesmeyer, M. Natrath and R. Gradinger, Influence of orthopaedic-technical aid on the kinematics and kinetics of the knee joint of patients with neuro-orthopaedic diseases, Brain Dev 26(4) (2004), 219-226.

[47] M. Leopando, Z. Moussavi, J. Holbrow, V. Chernick, H. Pasterkamp and G. Rempel, Effect of a Soft Boston orthosis on pulmonary mechanics in severe cerebral palsy, Pediatr Pulmonol 28 (1999), 53-58.

[48] M. Letts, D. Rathbone, T. Yamashita, B. Nichol and A. Keeler, Soft Boston orthosis in management of neuromuscular scoliosis: a preliminary report, J Pediatr Orthop 12 (1992), 470-474.

[49] M. Letts, L. Shapiro, K. Mulder and O. Klassen, The windblown hip syndrome in total body cerebral palsy, J Pediatr Orthop 4 (1984), 55-62. 
[50] Z. Li, J. Zhu and X. Liu. Deformity of lumbar spine after selective dorsal rhizotomy for spastic cerebral palsy, Microsurgery 28(1) (2008), 10-12.

[51] M.J. Loeters, C.G. Maathuis and M. Hadders-Algra, Risk factors for emergence and progression of scoliosis in children with severe cerebral palsy: a systematic review, Dev Med Child Neurol, 2010 Mar 19. [Epub ahead of print].

[52] P.R.G. Lucareli and M.D. Lima, Changes in joint kinematics in children with cerebral palsy while walking with and without a floor reaction ankle-foot orthosis, Clinics (Sao Paulo) 62(1) (2007), 63-68.

[53] D. Maltais, O. Bar-Or, V. Galea and M. Pierrynowski, Use of orthoses lowers the $\mathrm{O}(2)$ cost of walking in children with spastic cerebral palsy, Medicine and Science in Sports and Exercise 33(2) (2001), 320-325.

[54] M. Matthews, Articulating ankle foot orthoses incorporating neurophysiological footplate rectifications: a case study, Journal of the Association of Paediatric Chartered Physiotherapists (APCP) 2000, March: 21-24.

[55] A. Miller, T. Temple and F. Miller, Impact of orthoses on the rate of scoliosis progression in children with cerebral palsy, J Pediatr Orthop 16 (1996), 332-335.

[56] C. Morris, Orthotic management of children with cerebral palsy, Journal of Prosthetics and Orthotics 14(4) (2002), $150-158$

[57] C. Morris, B.E. Galuppi and P.L. Rosenbaum, Reliability of family report for the Gross Motor Function Classification System, Dev Med Child Neurol 46 (2004), 455-460.

[58] C Morris, J.J. Kurinczuk, R. Fitzpatrick and P.L. Rosenbaum, Who best to make the assessment? Professionals and families' classifications of gross motor function are highly consistent Archives of Disease in Childhood, Arch Dis Child 91 (2006), 675-679.

[59] C Morris, J.J. Kurinczuk, R. Fitzpatrick and P.L. Rosenbaum, Reliability of the Manual Ability Classification System in the UK, Dev Med Child Neurol 48 (2006), 950-953.

[60] C. Morris, Cerebral Palsy. In C Morris and L Dias. (eds) Paediatric Orthotics. Clinics in Developmental Medicine No. 175. Mac Keith Press: London, 2007.

[61] C. Morris and D. Condie, eds, Recent Developments in Healthcare for Cerebral Palsy: Implications and Opportunities for Orthotics. International Society for Prosthetics and Orthotics: Copenhagen. (2009) Available free at www. ispoint.org, Accessed 8 June 2010.

[62] K.A. Mossberg, K.A. Linton and K. Friske, Ankle-foot orthoses: effect on energy expenditure of gait in spastic diplegic children, Archives of Physical Medicine and Rehabilitation 71(7) (1990), 490-494.

[63] T. Nakamura and M. Ohamu, Hip abduction splint for use at night for scissor leg of cerebral palsy patients, Orthopedic Prosthetics Inter 34 (1980), 13-18.

[64] A. Näslund, M. Tamm, A.K. Ericsson and L. von Wendt, Dynamic ankle-foot orthoses as a part of treatment in children with spastic diplegia - parents' perceptions, Physiotherapy Research International 8(2) (2003), 59-68.

[65] National Horizon Scanning Centre. Lycra garments for cerebral palsy and movement disorders. Birmingham: National Horizon Scanning Centre. 2002. www.haps.bham.ac.uk/ publichealth/horizon/outputs/documents/2002/Lycragarmen ts.pdf, Accessed 8 June 2010.

[66] NHS Quality Improvement Scotland. Dynamic lycra splinting for children with cerebral palsy. NHS Quality Improvement Scotland Evidence Note \#11. 2005. http://www.
nhshealthquality.org/nhsqis/files/EN11\%20Final.pdf, Accessed 8 June 2010.

[67] J. Nicholson, R. Morton, S. Attfield and D. Rennie, Assessment of upperlimb function and movement in children with cerebral palsy wearing lycra garments, Developmental Medicine and Child Neurology 43 (2001), 384-391.

[68] R.M. Nuzzo, A simple treatment of genu recurvatum in ataxic and athetoid cerebral palsy, Orthopedics 9(9) (1986), 12231227.

[69] Y. Olafsson, H. Saraste and Z. Al-Dabagh, Brace treatment in neuromuscular spine deformity, J Pediatr Orthop 19 (1999), 376-379.

[70] S. Ounpuu, K.J. Bell, R.B. Davis, 3rd. and P.A. DeLuca, An evaluation of the posterior leaf spring orthosis using joint kinematics and kinetics, Journal of Pediatric Orthopedics 16(3) (1996), 378-384.

[71] E. Owen, Shank angle to floor measures of tuned 'anklefoot orthosis footwear combinations' used with children with cerebral palsy, spina bifida and other conditions. [Abstract] Gait and Posture, 2002. 16 (Supplement 1): S132.

[72] E. Owen, The point of 'point-loading rockers' in ankle foot orthosis footwear combinations used with children with cerebral palsy, spina bifida and other conditions. [Abstract] Gait and Posture, 2004. 20 (Supplement 1): S86.

[73] K. Ozer, S. Chesher and L. Scheker, Neuromuscular electrical stimulation and dynamic bracing for the management of upper-extremity spasticity in children with cerebral palsy, Developmental Medicine and Child Neurology 48 (2006), 559-563.

[74] R.J. Palisano, P. Rosenbaum, S. Walter, D. Russell, E. Wood and B. Galuppi, Development and reliability of a system to classify gross motor function in children with cerebral palsy, Dev Med Child Neurol 39 (1997), 214-223.

[75] R.J. Palisano, P. Rosenbaum, D. Bartlett and M.H. Livingston, Content Validity of the Expanded and Revised Gross Motor Function Classification System, Dev Med Child Neurol 50(10) (2008), 744-750.

[76] E.S. Park, C.I. Park, H.J. Chang, J.E. Choi and D.S. Lee, The effect of hinged ankle-foot orthoses on sit-to-stand transfer in children with spastic cerebral palsy, Archives of Physical Medicine and Rehabilitation 85(12) (2004), 2053-2057.

[77] T. Poutney, A. Mandy, E. Green and P. Gard, Management of hip dislocation with postural management, Child Care Health Dev 28 (2002), 179-185.

[78] J. Pritchett, The untreated unstable hip in severe cerebral palsy, Clin Orthop 173 (1983), 169-172.

[79] S.A. Radtka, S.R. Skinner, D.M. Dixon and M.E. Johanson, A comparison of gait with solid, dynamic, and no anklefoot orthoses in children with spastic cerebral palsy, Physical Therapy 77(4) (1997), 395-409.

[80] S.A. Radtka, S.R. Skinner and M.E. Johanson, A comparison of gait with solid and hinged ankle-foot orthoses in children with spastic diplegic cerebral palsy, Gait and Posture 21(3) (2005), 303-310.

[81] D. Reid and A. Sochaniwski, Influence of a hand positioning device on upper extremity control of children with cerebral palsy, Int J Rehabil Res 14 (1992), 15-29.

[82] D. Rennie, S. Attfield, R. Morton, F.J. Polak and J. Nicholson, An evaluation of lycra garments in the lower limb using 3$\mathrm{D}$ gait analysis and functional assessment (PEDI), Gait and Posture 12 (2000), 1-6.

[83] S. Rethlefsen, R. Kay, S. Dennis, M. Forstein and V. Tolo, The effects of fixed and articulated ankle-foot orthoses on gait 
patterns in subjects with cerebral palsy, Journal of Pediatric Orthopedics 19(4) (1999), 470-474.

[84] E. Ridgewell, F. Dobson, T. Bach and R. Baker, A systematic review to determine best practice reporting guidelines for AFO interventions in studies involving children with cerebral palsy, Prosthet Orthot Int 34(2) (2010), 129-145.

[85] J. Rodda and H.K. Graham, Classification of gait patterns in spastic hemiplegia and spastic diplegia: a basis for a management algorithm, Eur J Neurol 8(Suppl 5) (Nov 2001), 98-108.

[86] J.M. Rodda, L. Carson, H.K. Graham, M.P. Galea, R. Wolfe. Sagittal gait patterns in spastic diplegia, J Bone Joint Surg [Br] 86B (2004), 251-258.

[87] J. Romkes and R. Brunner, Comparison of a dynamic and a hinged ankle-foot orthosis by gait analysis in patients with hemiplegic cerebral palsy, Gait and Posture 15(1) (2002), 18-24.

[88] J. Romkes, A.K. Hell and R. Brunner, Changes in muscle activity in children with hemiplegic cerebral palsy while walking with and without ankle-foot orthoses, Gait and Posture 24(4) (2006), 467-474.

[89] S. Ronan and J.T. Gold, Nonoperative management of spasticity in children, Childs Nervous System 23(9) (2007), 943956.

[90] P. Rosenbaum, N. Paneth, A. Leviton, M. Goldstein and M. Bax, Definition and Classification Document, in The Definition and Classification of Cerebral Palsy, Dev Med Child Neurol 49 (2007), 8-14.

[91] N. Saito, S. Ebara, K. Ohotsuka, H. Kumeta and K. Takaoka, Natural history of scoliosis in spastic cerebral palsy, The Lancet 351 (1998), 1687-1692.

[92] R.J. Sankey, D.M. Anderson and J.A. Young, Characteristics of ankle-foot orthoses for management of the spastic lower limb, Developmental Medicine and Child Neurology 31 (1989), 466-470.

[93] J.M. Sansone, D. Mann, K. Noonan, D. Mcleish, M. Ward and B.J. Iskandar, Rapid progression of scoliosis following insertion of intrathecal baclofen pump, J Pediatr Orthop 26 (2006), 125-128.

[94] H. Seneran, S.A. Shah, A. Presedo, K.W. Dabney, J.W. Glutting and F. Miller, The risk of progression of scoliosis in cerebral palsy patients after intrathecal baclofen therapy, Spine 32 (2007), 248-254.

[95] H. Senaran, S. Shah, J. Glutting, K.W. Dabney and F. Miller, The associated affects of untreated unilateral hip dislocation in cerebral palsy scoliosis, J Pediatr Orthop 26 (2006), 769772.

[96] F. Shecker, S. Chesher and S. Ramirez, Neuromuscular electrical stimulation and dynamic bracing as a treatment for upper-extremity spasticity in children with cerebral palsy, $J$ Hand Surg [Br] 24 (1999), 226-232.

[97] J.S. Shilt, L.P. Lai, M.N. Cabrera, J. Frino and B.P. Smith, The impact of intrathecal baclofen on the natural history of scoliosis in cerebral palsy, J Pediatr Orthop 28 (2008), 684 687.

[98] S. Sienko-Thomas, C.E. Buckon, S. Jakobson-Huston, M.D. Sussman and M.D. Aiona, Stair locomotion in children with spastic hemiplegia: the impact of three different ankle foot orthosis (AFOs) configurations, Gait and Posture 16(2) (2002), 180-187.

[99] S.J. Smiley, F.S. Jacobsen, C. Mielke, R. Johnston, C. Park and G.J. Ovaska, A comparison of the effects of solid, articulated, and posterior leaf-spring ankle-foot orthoses and shoes alone on gait and energy expenditure in children with spastic diplegic cerebral palsy, Orthopedics 25(4) (2002), 411-415.

[100] B. Soo, J. Howard, R. Boyd, S.M. Reid, A. Lanigan, R. Wolfe, D. Reddihough and H.K. Graham, Hip displacement in cerebral palsy, J Bone Joint Surg Am 1 (2006), 121-129.

[101] D.A. Spiegel, R.T. Loder, K.A. Alley, S. Rowley, S. Gutknecht, D.L. Smith-Wright and M.E. Dunn, Spinal deformity following selective dorsal rhizotomy, J Pediatr Orthop 24(1) (2004), 30-36.

[102] J. Stallard and P.J. Woollam, Transportable two-dimensional gait assessment: routine service experience for orthotic provision, Disability and Rehabilitation 25(6) (2003), 254-258.

[103] P. Steinbok, T. Hicdonmez, B. Sawatzky, R. Beauchamp and D. Wickenheiser, Spinal deformities after selective dorsal rhizotomy for spastic cerebral palsy, J Neurosurg 102(4 Suppl) (2005), 363-373.

[104] Surveillance of Cerebral Palsy in Europe (SCPE). Surveillance of cerebral palsy in Europe: a collaboration of cerebral palsy surveys and registers, Dev Med Child Neurol 42 (2000), 816-824.

[105] D.H. Sutherland and J.R. Davids, Common gait abnormalities of the knee in cerebral palsy, Clin Orthop Relat Res (1993), 139-147.

[106] C. Tardieu, A. Lespargot For how long must the soleus muscle be stretched each day to prevent contracture? Dev Med Child Neurol 30(1) (1988), 3-10.

[107] T. Terjesen, J. Lange and H. Steen, Treatment of scoliosis with spinal bracing in quadriplegic cerebral palsy, Dev Med Child Neurol 42 (2000), 448-454.

[108] N.S. Thompson, T.C. Taylor, K.R. McCarthy, A.P. Cosgrove and R.J. Baker, Effect of a rigid ankle-foot orthosis on hamstring length in children with hemiplegia, Developmental Medicine and Child Neurology 44(1) (2002), 51-57.

[109] M. Turi and V. Kalen, The risk of spinal deformity after selective dorsal rhizotomy, J Pediatr Orthop 20(1) (2000), 104-107.

[110] L. Van Gestel, G. Molenaers, C. Huenaerts, J. Seyler and K. Desloovere, Effect of dynamic orthoses on gait: a retrospective control study in children with hemiplegia, Developmental Medicine and Child Neurology 50(1) (2008), 63-67.

[111] Z. Vekerdy, Management of seating posture of children with cerebral palsy by using thoracic-lumbar-sacral orthosis with non-rigid SIDO frame, Disabil Rehabil 29 (2007), 14341441.

[112] K.A. Wesdock and A.M. Edge, Effects of wedged shoes and ankle-foot orthoses on standing balance and knee extension in children with cerebral palsy who crouch, Pediatric Physical Therapy 15(4) (2003), 221-231.

[113] D.E. Westberry, J.R. Davids, J.C. Shaver, S.L. Tanner, D.W. Blackhurst and R.B. Davis, Impact of ankle-foot orthoses on static foot alignment in children with cerebral palsy, Journal of Bone and Joint Surgery-American Volume 89A(4) (2007), 806-813.

[114] H. White, J. Jenkins, W.P. Neace, C. Tylkowski and J. Walker, Clinically prescribed orthoses demonstrate an increase in velocity of gait in children with cerebral palsy: a retrospective study, Developmental Medicine and Child Neurology 44(4) (2002), 227-232.

[115] H. Wilson, N. Haideri, K. Song and D. Telford. Ankle-foot orthoses for preambulatory children with spastic diplegia, Journal of Pediatric Orthopedics 17(3) (1997), 370-376.

[116] T. Winters, J. Gage and R. Hicks, Gait patterns in spastic hemiplegia in children and adults, $J$ Bone Joint Surg [Am] 69A (1987), 437-441. 
[117] World Health Organization: International Classification of Functioning, Disability and Health (ICF). Geneva: World Health Organization, 2001.

[118] A. Yasukawa, J. Lulinski, L. Thornton and P. Jaudes, Improving elbow and wrist range of motion using a dynamic and static combination orthosis, J Prosthet Orthot 20 (2008), 41-48.
[119] A. Yasukawa, B. Malas and D. Gaebler-Spira, Efficacy for maintenance of elbow range of motion of two types of orthotic devices: A case series, J Prosthet Orthot 15 (2003), $72-75$. 